\title{
Identifying behavioural predictors of small power electricity consumption in office buildings
}

Article

Accepted Version

Tetlow, R., van Drokelaar, C., Beaman, P., Elmualim, A. A. and Couling, K. (2015) Identifying behavioural predictors of small power electricity consumption in office buildings. Building and Environment, 92. pp. 75-85. ISSN 0360-1323 doi: https://doi.org/10.1016/j.buildenv.2015.04.009 Available at https://centaur.reading.ac.uk/40271/

It is advisable to refer to the publisher's version if you intend to cite from the work. See Guidance on citing.

To link to this article DOI: http://dx.doi.org/10.1016/j.buildenv.2015.04.009

Publisher: Elsevier

All outputs in CentAUR are protected by Intellectual Property Rights law, including copyright law. Copyright and IPR is retained by the creators or other copyright holders. Terms and conditions for use of this material are defined in the End User Agreement.

www.reading.ac.uk/centaur 
Central Archive at the University of Reading

Reading's research outputs online 


\title{
Identifying behavioural predictors of small power electricity consumption in office buildings
}

\author{
Richard M. Tetlow ${ }^{1,5^{*}}$, Chris van Dronkelaar ${ }^{2,6}$, C. Philip Beaman ${ }^{3}$, Abbas A. Elmualim ${ }^{4}$ and Kevin \\ Couling ${ }^{5}$ \\ ${ }^{1}$ Technologies for Sustainable Built Environments, University of Reading, UK \\ ${ }^{2}$ The Bartlett School of Environment, Energy and Resources, University College London, UK \\ ${ }^{3}$ School of Psychology \& Clinical Language Sciences, University of Reading, UK \\ ${ }^{4}$ School of Construction Management and Engineering, University of Reading, UK \\ ${ }^{5}$ AECOM, Bristol, UK \\ ${ }^{6}$ BuroHappold Engineering, London, UK \\ *Corresponding email: r.m.tetlow@pgr.reading.ac.uk
}

\begin{abstract}
It is widely accepted that there is a gap between design and real world operational energy consumption. The behaviour of occupants is often cited as an important factor influencing building energy performance. However, its consideration, both during design and operation, is overly simplistic, often assuming a direct link between attitudes and behaviour. Alternative models of decision making from psychology highlight a range of additional influential factors and emphasise that occupants do not always act in a rational manner. Developing a better understanding of occupant decision making could help inform office energy conservation campaigns as well as models of behaviour employed during the design process.
\end{abstract}

This paper assesses the contribution of various behavioural constructs on small power consumption in offices. The method is based upon the Theory of Planned Behaviour (TPB) which assumes that intention is driven by three factors: attitude, subjective norms, and perceived behavioural control, but we also consider a fourth construct: habit measured through the Self-Report Habit Index (SRHI). A questionnaire was issued to 81 participants in two UK offices. Questionnaire results for each behavioural construct were correlated against each participant's individual workstation electricity consumption.

The intentional processes proposed by TPB could not account for the observed differences in occupants' interactions with small power appliances. Instead, occupants were interacting with small power "automatically", with habit accounting for $11 \%$ of the variation in workstation energy consumption. The implications for occupant behaviour models and employee engagement campaigns are discussed.

\section{Keywords}


Electricity consumption, occupant behaviour, offices, small power, habits

\section{INTRODUCTION}

According to calculations based on UK energy consumption statistics, in 2013 the operation of non-domestic buildings was responsible for around $12 \%$ of total $\mathrm{UK} \mathrm{CO}_{2}$ emissions with commercial offices alone representing about 1.1\% (DECC, 2014). To promote large scale reduction of emissions in this sector, the UK Government has tended to rely on legislative tools. For instance, successive revisions of Part $L$ since 2002 have seen the introduction of gradually stricter targets for $\mathrm{CO}_{2}$ emissions abatement (DCLG, 2013). Whilst this has led to greater demand for energy efficient commercial properties, evidence from post-occupancy evaluations (POE) routinely show that this low carbon design intent only rarely results in low carbon in operation. For example, data from CarbonBuzz indicate that office buildings can consume as much as 1.8 times more energy than indicated by the initial design calculations (Ruyssevelt \& Robertson, 2013).

The failure of this legislative approach to deliver the anticipated energy reductions is partly due to its one-dimensional nature. Carbon emissions abatement is primarily sought through the promotion of "technological" solutions such as improved building fabric efficiency, increased efficiency of building services, and incorporation of low/ zero carbon technologies (Azar \& Menassa, 2012). This focus on technology addresses only part of the problem as it does not adequately account for the behaviour of the occupants which is regularly cited as a key determinant of actual in-use building energy performance (Yu, et al. 2011; Fabi, et al. 2012; Hong \& Lin, 2012, Hong et al., 2015) and can considerably reduce the effectiveness of some technological interventions intended to reduce $\mathrm{CO}_{2}$ emissions (Lo et al., 2012). Postoccupancy investigations routinely reveal examples of occupants using technological systems contrary to the building's original design intent. For example, Passive Infra-Red (PIR) sensors to automatically switch off lighting do not necessarily attain the anticipated energy savings because occupants can modify their behaviour as a direct result of their implementation (Pigg et al., 1996), unanticipated small power loads are introduced (Menezes, et al. 2012b), and carefully designed heating, ventilation, and air-conditioning (HVAC) strategies are compromised (Page, et al. 2008). The designers of any technological system often assume that the intended end-users will possess the same conceptual model of how the system operates as they do, neglecting the fact that the end-users were not privy to the original design decisions. When the end user's conceptual model of operation differs from that of the designer there is a "communication gap" (Norman, 2013). In the case of building systems and controls there is often little or no direct communication between the designer and the end-user (either the facilities manager or occupants) to indicate appropriate use. Consequently, the occupants in particular are left to infer the operation, and the design intent, of any technological system installed. This oversight directly contributes to instances of users operating building systems "inappropriately" (i.e. 
contrary to the design intent) and inefficiently, significantly contributing to the observed difference between anticipated and actual energy levels.

In an effort to predict the energy impact of occupant behaviour numerous models have been developed (e.g. Newsham, 1994; Love, 1998; Nicol, 2001; Reinhardt, 2004; Herkel et al., 2008; Yun \& Steemers, 2008). In general these have taken a fairly superficial approach to modelling behaviour, assuming that action is triggered primarily by physical changes in environmental variables such as external temperature or illuminance level. To account for the high level of variability of occupant behaviour observed during field studies many models also propose categorising building occupants into different "user types" which regularly include explicit or implicit reference to the occupant's environmental attitudes (Reinhardt, 2004; Bourgeois, 2005; Fabi et al., 2012; Hong \& Lin, 2012; Turner \& Hong, 2013). However, from a psychological viewpoint this representation of attitude alone as determining behaviour is demonstrably insufficient. Indeed, the fallacy that a given individual's behaviour is determined by their attitude is known within social psychology as the "fundamental attribution error" (Ross, 1977) and it is noteworthy that this attribution is far more frequently applied to others than to one's own behaviour - for which situational variables are more frequently cited (Storms, 1973). Similarly, there is a documented "intention-behaviour gap" (reviewed by Sheeran, 2002) whereby positive intention to act does not perfectly predict future action.

This paper attempts to apply insights from psychology to assess occupant interactions with small power appliances and resulting energy consumption. It reports on an investigation to assess the relative importance of four behavioural predictors (highlighted as important factors in the decision making process by psycho-social models of behaviour) on average daily workstation electricity consumption in two open plan office buildings in the UK, one in Bristol and one in London. The assessment method is through an online questionnaire, the development and implementation of which are described in detail. The implications of the results for both the modelling of occupant behaviour during the design of new buildings and for influencing occupant behaviour in existing buildings are discussed.

\section{OCCUPANT BEHAVIOUR MODELS}

Although building simulation software programmes for modelling thermal and building service performance are now relatively mature (Haldi \& Robinson, 2009) the interaction of occupants with the building's systems and controls, which can arguably have an even greater influence than thermal processes, is considered only simplistically (Hoes et al., 2009). For example, current energy modelling during the design stage makes the rather crude assumption that certain systems are consistently in operation during default occupancy profiles (Hoes et al., 2009; Menezes et al., 2012a). While this is currently is acceptable engineering practice, in reality occupant interactions with building systems and 
controls are much more dynamic and, consequently, occupant behaviour is the most significant cause of uncertainty in the prediction of building energy use (Hong \& Lin, 2012).

In an effort to improve this situation, various models capable of predicting occurrences of occupant related energy use have been developed which are compatible with existing building simulation tools (e.g. Newsham, 1994; Love, 1998; Nicol, 2001; Reinhardt, 2004; Herkel et al., 2008; Yun \& Steemers, 2008). While these models have advanced the understanding of occupant interactions with the built environment, to date none have achieved any traction within the construction industry. One reason for this, as Turner and Hong (2013) highlight, is that these models have been developed by different research groups focusing on different variables and employ a wide range of data collection and analysis techniques. Consequently, the resulting models are difficult to compare to one another.

This variability amongst built environment models of occupant behaviour also reflects the high variability of behaviour observed amongst occupants in field studies. To address this, there have been many attempts to distinguish between different types of occupants. For example, Reinhardt (2004) developed a sophisticated and influential lighting algorithm, "Lightswitch-2002", to predict the probability of occupants switching lights on and off when arriving and leaving cellular offices. Building on Love's (1998) initial reference to different levels of use between occupants, Reinhardt conceived of four different "user types" based on whether the occupant's use of artificial lighting was dependent or independent of daylight. Bourgeois (2005) created an expansive model for predicting interaction with both windows and lighting based on Nicol (2001) and Reinhardt's (2004) earlier work. This further developed Reinhardt's distinction between different user types with Bourgeois proposing that occupants can be represented as "active" (i.e. use these systems a lot) or "passive" (i.e. never use these systems). More recently, Hong and Lin (2012) categorised occupants in private offices into three different work styles: "austerity" - occupants are proactive in saving energy, "standard" - represents the average energy use of the majority of occupants, and "wasteful" - occupants have no motivation to save energy. When these categories were used as inputs during an energy modelling exercise, the results showed corresponding increases or decreases in energy consumption. Leading on from this, Turner and Hong (2013) stated that an occupant's energy attitude is an important driver for any behaviours which result in energy consumption. They suggested that occupants can be usefully categorised as "energy frugal", "energy indifferent", or "energy profligate". Fabi et al. (2012) also claimed that it is possible to differentiate between users' behaviours typologies depending on how they interact with a building. For instance, from an energy perspective occupants could be classified as "energy saving users" or "energy wasting users". In later related work, Fabi et al. (2014) also drew a distinction between "active" and "passive" situations for occupant interaction with lighting controls and they proposed different models to account for these different situations. 
These models then have attempted to broadly categorise occupants in a way that seems to implicitly assume stability of user-type as a physical parameter across time, building type, and system. Models can also be viewed either as purely behaviouristic, within which parameters are merely a mechanism to generate energy use data and the actual psychological drivers of those models are unimportant or the parameters may be intended to reflect some underlying psychological reality about the occupants in question. In the former case, the identification of user categories with psychological states is incidental. In the latter (e.g., Turner \& Hong, 2013), the identification of occupant types with particular aspects of occupant psychology - in particular with attitude - is worthy of further consideration. Arguably, the incorporation of psycho-social determinants within built environment behavioural models is a step forward as it allows for particular aspects of psychology which could potentially drive energy use to be identified and targeted using appropriately designed interventions. For example, from a psychological perspective this representation of attitude alone as determining behaviour is unsatisfactory as it neglects well-established research which indicates that even stable personality traits (such as the "big five" personality types, McCrae \& John, 1992) are relatively poor predictors of behaviour when compared to a more detailed assessment (Paunonen \& Ashton, 2001). Additionally, alternative psycho-social models of decision making indicate that, in addition to attitudes, other factors are important in forming behaviour - in particular habit is a crucial determinant in energy-related behaviours (Triandis, 1977; Chatterton, 2010; Darnton et al., 2011). A question that this paper attempts to answer is whether it is possible to break down individual differences in energy consumption within buildings into their component parts and whether, on doing so, there is a role played by habit in contributing to variations in energy use. Identifying such a behavioural predictor for energy use is orthogonal to the aims of traditional energy-use models because, here, we are not aiming to account for, or predict, the behavioural component of the total energy use of a building. Rather, the aim is to identify the psychological basis for individual differences in energy use within a building since only by doing so can individual barriers to reducing energy use be identified and appropriate interventions designed.

\subsection{Small power consumption}

Within office buildings, small power appliances typically account for around $20 \%$ of total energy consumption (BRECSU, 2000). Interestingly, inappropriate use of small power appliances by occupants (i.e. leaving appliances on when not required) receives little attention in behavioural models which tend to focus on as window opening and lighting use (with the notable exception of Nicol (2001)). This is perhaps because, in the UK, unregulated loads (i.e. loads not taken into account during energy modelling for compliance with Part L of the Building Regulations) prove difficult for design teams to accurately anticipate as they have little influence over how a completed building will be fitted out and used (UKGBC, 2014). Nonetheless, small power appliance use is one of the main ways that occupants can 
adversely affect actual energy consumption in every office building regardless of ventilation or lighting strategy. For example, during energy audits of six office buildings in Southern Africa, Masoso and Grobler (2010) discovered that more energy was used outside of working hours (56\%) than during working hours (44\%), partly as a result of occupants leaving small power appliances on at the end of the day. Similarly, in two UK offices, Mulville et al. (2014) found that up to $23 \%$ of total electricity use was consumed outside of standard working hours. Concentrating only on electricity consumption for computers, Menezes (2013) carried out an in-depth study across two office buildings in the UK. She discovered that electricity consumption for computers was not only significantly influenced by the computer specification (i.e. laptops were more likely to be turned off at the end of the day than desktops) but also by the job role of the occupant. Employees in higher grade positions used their computers less frequently to fulfil their work requirements. Evidence from studies such as these serves to highlight the high potential for workstation electricity conservation in typical office buildings.

In an attempt to motivate conservation around small power appliances, many offices implement occupant engagement campaigns designed to raise awareness and alter attitudes. Almost ubiquitously, these involve the provision of information to employees through emails, posters, and training about the pro-environmental benefits of altering their behaviour (Carbon Trust, 2013). This type of engagement is clearly predicated on the same assumption prevalent in built environmental models of occupant behaviour - that there is a direct link between pro-environmental attitudes and observable pro-environmental behaviour. These types of interventions are based on the "information deficit" model (Kollmuss \& Agyeman, 2002) which assumes that people will act rationally on information provided to them and modify their behaviour to achieve the optimal outcome. However, the widespread failure of many previous information intensive mass-media campaigns (e.g. "Act on $\mathrm{CO}_{2}{ }^{\prime \prime}$ ) to generate the anticipated savings (Owens \& Driffil, 2008) has called into question this approach. There is growing evidence, particularly from the field of behavioural economics, that shows whilst presenting people with information may change attitudes and deliberate behaviour, it often has little appreciable effect on behaviours which are automatic and habitual (Ariely, 2009); a situation which is analogous to the intentionbehaviour gap previously discussed (Sheeran, 2002).

\section{PSYCHOLOGICAL MODELS OF DECISION-MAKING AND ACTION}

\subsection{Dual process models of cognition}

Dual process models of cognition can help to explain the inability of the pro-environmental attitudes of an occupant to reliably predict their actual behaviour. Essentially, dual process models posit that human decision making is governed by two separate systems; System 1 which is automatic, fast and responds directly to the surrounding environment, and System 2 which is conscious and controlled but slow and requires a certain degree of effort to 
employ (Evans, 2008; Kahneman, 2011). Although a strict division into two distinct systems is an oversimplification, dual process models provide a useful framework by which to consider occupant behaviour. "Errors" within either of these two systems could, within the context of the built environment, result in "inappropriate" actions culminating in unnecessary energy consumption. From this perspective it can be seen that information intensive campaigns are likely to fail because they focus disproportionately on conscious System 2 and do not adequately target behaviour stemming from the more automatic (and more easily deployed) System 1. Kahneman (2011) reviews repeated demonstrations of people defaulting to System 1 in many situations rather than expending the requisite effort to use the more considered and accurate System 2. Additionally, previous studies have shown that, because habits are triggered by associated contexts, they will often supersede deliberative intentions and dictate behaviour in those settings (Gardner et al., 2012) particularly where conscious attention is directed elsewhere (Norman \& Shallice, 1986). Consequently, where habit and intention are in direct conflict the resulting action is often likely to proceed in line with habit rather than intention.

\subsection{Theory of planned behaviour}

Originally developed by Ajzen (1991) the Theory of Planned Behaviour (TPB) is one of the most widely applied models of intention to act (Armitage \& Conner, 2001). Essentially, the TPB proposes that human action is determined by conscious intention which is formed through a combination of three behavioural constructs: attitude, subjective norms and perceived behavioural control (PBC). Quantifying these three "predictors" for an individual allows the likelihood that they will carry out a particular action to be estimated.

Additionally, if these predictors can then be subsequently adjusted (i.e. through behavioural interventions) the possibility of the action being performed can be directly influenced. Although the validity of the TPB has been demonstrated across a range of behavioural domains (see Armitage \& Conner (2001) for a review), applications of the TPB in the assessment of pro-environmental behaviours are rare. However, the TPB has been previously applied to energy consumption in the domestic sector. Gill et al. (2010) created a questionnaire following Francis et al.'s (2004) framework which quantified energy efficient behaviour in terms of the three TPB behavioural constructs. The questionnaire was implemented at a low carbon village in the UK and the TPB scores for each participant were correlated with their household's monthly energy consumption. The results of this showed that deliberate energy efficient behaviours accounted for around $51 \%$ and $37 \%$ of the variance in heat and electricity use respectively between the homes. Although a compelling finding, the sample size of only 15 households limits the reliability of this result and the potential to generalise this to other buildings.

\subsection{Theory of interpersonal behaviour}

The TPB has been useful in explaining a range of behaviours but its capacity to describe energy related behaviours may be limited as it only addresses intentional (i.e. System 2) 
behaviour. Much behaviour with the largest environmental impact could be considered habitual (i.e. System 1), such as recycling, travel choice, or switching off appliances when not required (Darnton, et al., 2011). To account for this deficiency, an alternative model, the Theory of Interpersonal Behaviour (TIB), is considered. The TIB has risen to prominence over the last decade and has recently been recommended by several researchers specifically for the analysis of pro-environmental behaviour where habits are clearly an important consideration (Chatterton, 2011; Darnton, et al., 2011). The TPB and TIB are broadly similar in structure. For instance, both (in general terms) take into account attitudes, subjective norms, and perceived behavioural control (although TIB refers to this as "facilitating conditions"). The main distinction between the two lies in the relative importance attributed to conscious intent (i.e., System 2). While the TPB presents behaviour as under the individual's conscious control, the TIB proposes that the level of conscious control decreases as the behaviour becomes more habitual (Bamberg \& Schmidt, 2003). Put simply, the TIB suggests that the construct of habit needs to be considered as an additional and separate predictor of behaviour which effectively bypasses conscious intention. From this perspective, the configuration of the TIB means it can be considered the social psychology archetype of the dual process models of cognition (Darnton, et al., 2011). To allow comparison with earlier work (Menezes et al., 2012b), the approach that we have taken in this study is to consider the three predictors of TPB, but to also include habit as a fourth separate predictor. Figure 1 illustrates this notion.



Figure 1: The Theory of Planned Behaviour, adapted from Ajzen (1991) with the inclusion of the behavioural construct "habit".

\subsection{Habit}


Most of the time automatic behaviour stemming from System 1 is beneficial as it ensures that our daily behaviour runs smoothly and consistently with little conscious effort (e.g., gears can be changed more or less automatically when driving, freeing conscious awareness to scan the road for potential hazards ahead). However, such habitual behaviour may give rise to "errors" which, with regards to occupant interactions with building systems and controls, can result in unintended energy consumption. Habits are notoriously difficult to alter and people tend to repeat behaviours even if they consequently achieve sub-optimal outcomes. Huebner et al. (2013) used semi-structured interviews in 41 UK households and identified habits (defined as people "being used to behave in a certain way") as the most significant barrier to changing behaviour. This is likely to be similarly true in a non-domestic setting where Mulville et al.'s (2014) study of individual workstation electricity consumption highlighted the importance of considering habitual behaviour if energy conservation is to be successfully motivated.

To be able to alter habits it is first necessary to be able to adequately measure them. In the original version of the TIB proposed by Triandis (1977), habit was defined simply as the frequency of past behaviour. This definition has been widely criticised (Chatterton, 2011; Darnton et al., 2011) and it is now generally accepted that a specific behaviour will require not just frequency of past behaviour but also automaticity, if it is to become habitualised. Automaticity can be defined as the absence of deliberation or conscious thought (Darnton et al., 2011) and as such can be directly contrasted against consciously controlled mental processes (Norman \& Shallice, 1986). As pointed out by Evans (2008), from this perspective automaticity is analogous to System 1 decision making. This more sophisticated definition of habit as automaticity may be quantified. Verplanken and Orbell (2003) developed the SelfReport Habit Index (SRHI), comprising of 12 short questions, as a way of calculating the extent to which a particular behaviour is habitual for an individual although, as Gardner et al. (2012) point out, of the SRHI's 12 questions, only seven actually measure automaticity. Gardener el al. (2012) argue that of the remaining five, one measures frequency, one measures identity, and the remaining three are essentially irrelevant.

As far as we are aware, no previous studies have attempted to apply elements of the TPB and the TIB concurrently to account for behaviours resulting in inadvertent energy consumption within the built environment. However, in one particularly relevant study, Bamberg and Schmidt (2003) attempted to compare the predictive power of the TPB to the TIB by applying them both to the car use of 608 students travelling to a university campus in Giessen, Germany. They discovered that the TIB was more predictive of behavioural outcomes than the TPB and concluded that this was mainly due to the model's emphasis on habit. In this study therefore, we examine the extent to which differences in small-power use can be accounted for by System 2, controlled processes which may be corrected by appeals to change attitudes and intentions, or by System 1, automatic and habitual 
processes which - being largely outside of conscious control - will require a different set of interventions.

\section{PROCEDURE}

In a previous study, Menezes et al. (2012b) applied the TPB to assess the relationship between the action of switching lighting and appliances off when not in-use to the combined electricity use for small power and lighting in a multi-tenanted office building in London, UK. Median scores for each of the TPB's three predictors for participants in each sub-metered zone were correlated against monthly electricity consumption. Analysis of the results found that the only predictor which showed a significant correlation with monthly electricity consumption was PBC. The conclusion drawn was that, in the investigated office building, around $17 \%$ of the variation in monthly electricity consumption could be directly attributed to the behaviour of the occupants; seemingly the more control occupants perceived that they had over lighting and small power appliances the less electricity they consumed. Although an intriguing finding, this study had several notable shortcomings. Firstly, due to an inability to adequately ascribe energy consumption to different individuals, questionnaire scores for the TPB were necessarily averaged across each sub-metered zone. As well as drastically reducing the sample size (and therefore the sensitivity and reliability of the study) the TPB is typically applied to individuals and has not been previously studied using groups. Secondly, due to the arrangement of sub-metering in the surveyed office building, actions regarding lighting and small power had to be considered together in the same questionnaire. Feedback from some participants indicated that, in a number of questions, they would have supplied different answers if lighting and small power were considered separately. Thirdly, and perhaps most significantly, the TPB only considers planned behaviour. Therefore the study only assessed System 2 decision making and is unable to account for the (potentially larger) contribution to inadvertent energy use in the built environment through automatic and habitual System 1.

The study described in this paper builds on the previous study by addressing these three limitations. It achieves this by using a direct measure of electricity consumption for each participant's workstation. This allows the participant's scores for each behavioural construct to be correlated with an individual measure of energy consumption, simultaneously shifting the focus of the study to only small power appliances, not small power appliances and lighting in combination. Obviating the need to average scores for the behavioural predictors across sub-metered zones allows for an increased sample size and hence a more statistically powerful study and conceptually clearer design. To additionally account for the contribution to behaviour through automatic System 1 a fourth predictor is considered, habit which is measured through the SRHI. Our hypothesis is that, due to the probable habitual nature of workstation electricity consumption, the construct of habit should provide a stronger correlation than the other predictors. 


\subsection{Participants}

The study was undertaken at two separate UK open plan office buildings: Building 1 in Bristol and Building 2 in London, which provide work place facilities for around 100 and 200 occupants respectively. Employees at both buildings work for different built environment engineering consultancies. There is one notable difference between the two; Building 1 is fully air-conditioned, while Building 2 is naturally ventilated. Generally, the work carried out in both buildings is desk-based and there is no local control over lighting or HVAC systems (apart from manually openable windows in Building 2). There are also no management systems in place to automatically power down small power appliances at the end of the day. These two buildings were chosen because the authors had ready access to them, they represented similar sample populations, and the majority of the employees had their own designated desks which would allow workstation electricity consumption to be monitored and attributed to each participant.

\subsection{Assessing behavioural constructs}

The method of producing the questionnaire to quantify the behavioural predictors for each individual is outlined in Figure 2. The questionnaire used for this study was in essence the same as the one developed and implemented for the previous study (Menezes, et al., 2012b) using the framework proposed by Francis et al. (2004). However the behaviour under investigation was adjusted to "switching off small power appliances when not in use". 


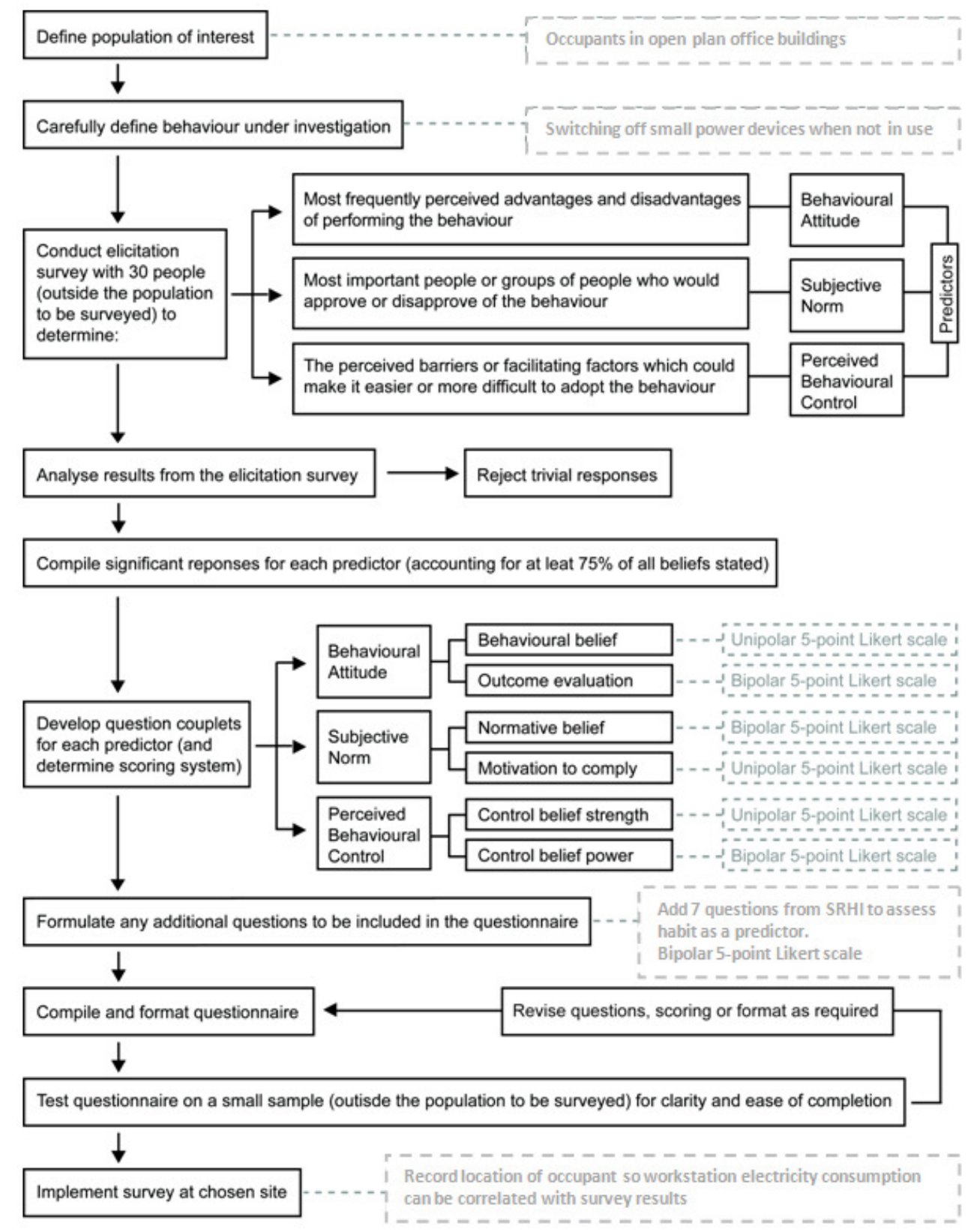

Note: Information within dashed boxes relate to choices / actions specific to this study.

Figure 2: Flow chart detailing method of creating surveys based on TPB and habit adapted from Menezes et al. (2012b) for this study.

During development of the questionnaire an elicitation survey was issued to around 30 people outside of the population to be surveyed to establish the dominant behavioural factors motivating decisions regarding the target behaviour (see Figure 2). The elicitation survey comprised of six open ended questions. Respondents were asked to give three responses for each question which were taken as representing their significant beliefs regarding each predictor. Specifically, the questions related to the respondent's beliefs at their workplace around the advantages and disadvantages of switching off appliances when 
they are not in use (attitudes), individuals or groups who would approve or disapprove of them switching off appliances when not in use (subjective norms), and the factors which make it easier or more difficult for them to switch off appliances when not in use (perceived behavioural control). The results of the elicitation survey were thematically analysed and the most frequent themes were phrased into question couplets to obtain both direct and indirect (belief-based) measure of each predictor. For example, "If I switch off office appliances when they are not in use I will be helping my company to save money." (direct) and "Helping my company to save money is..." (indirect).

This produced a questionnaire with six groups of five questions (two groups for each of the three constructs: attitude, subjective norms and perceived behavioural control). Scoring scales were established for each group of questions using a 5-point scale. The direction of the scale was bi-polar ( -2 to +2$)$ for the direct measures and uni-polar $(+1$ to +5$)$ for the indirect measures. Final scores for each predictor were scored according to Francis et al.'s (2004) method which, for each question couplet, involves multiplying the direct measure with the indirect measure using the following equations:

Attitude score:

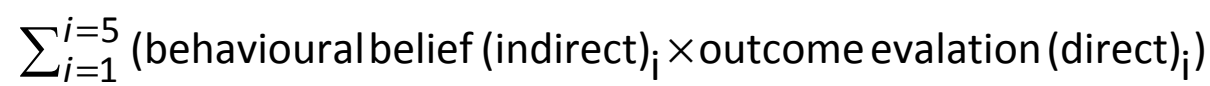

Subjective norms score:

$$
\left.\sum_{i=1}^{i=5}(\text { normative belief (indirect) })_{\mathrm{i}} \times \text { motivation to comply }(\text { direct })_{\mathrm{i}}\right)
$$

Perceived behavioural control score:

$$
\left.\sum_{i=1}^{i=5}(\text { control strength (indirect })_{\mathrm{i}} \times \text { control power }(\text { direct })_{\mathrm{i}}\right)
$$

For example, if the participant answered "strongly agree" for the direct measure and "strongly agree" for the indirect measure for one of the 5 question couplets for attitude then the score would be 2 (direct) $\times 5$ (indirect) $=10$. Alternatively, if the participant answered "strongly disagree" for the direct measure but "strongly agree" for the indirect measure for one of the 5 question couplets for attitude then the score would be -2 (direct) $x$ 5 (indirect) $=-10$. Therefore for each of the three predictors (attitudes, subjective norms, and $\mathrm{PBC}$ ) each participants score could range from -50 to 50 .

In line with the research findings of Gardner et al. (2012), seven questions from the original 12 Self-Report Habit Index (SRHI) were chosen based on their reference to "automaticity". These seven questions were scored using a 5-point bi-polar scale ranging from "strongly agree" to "strongly disagree". The scores for each of these questions were added together to provide a range of scores for the construct of habit from +14 to -14 . 
Questionnaires for both offices were administered online to all employees. Building 1 achieved 64 responses and Building 2 achieved 44 responses. Additional questions were included to determine how many days on average each participant worked in the offices and whether they "hot-desked" or not. Responses to these questions were used as a basis to select the participants most suitable for the monitoring of workstation electricity consumption with preference given to those who had their own desk and were in the office most often.

\subsection{Workstation electricity consumption}

Workstations of consenting participants were fitted with wireless plug energy monitors. The plug monitors were tested in isolation and were discovered to have an installed load of less than $1 \mathrm{~W}$. A standard six-way plug adaptor was fitted directly into each of the plug energy monitors and all of the participant's workstation appliances were connected into this adaptor. The adaptor was then hidden in the desk tray at the rear of the desk. At Building 1 , 48 workstations were fitted with monitors. At Building 2, 37 workstations were fitted with monitors.

The plug energy monitors were connected wirelessly through ZigBee to a data logger (controller unit) located at a central point in the offices. The plug energy monitors continuously relayed 6-minute electricity consumption data back to the controller unit which stored the data.

Workstation electricity consumption in each building was monitored for a period of four weeks including non-working days. Building 1 was monitored over April 2014 and Building 2 was monitored over July 2014. At the end of the four week study periods, analysis of the workstation electricity data revealed that at Building 1 one plug monitor recorded no data, two recorded spurious readings (e.g. negative) for an undetermined reason, and one participant moved about the office to several different locations. For these reasons the results for these four participants were excluded from final analysis leaving a sample of 44 participants. At Building 2 no problems with data collection were encountered and no participants needed to be excluded from analysis leaving a sample of 37 . Therefore the combined sample size was 81 .

To enable comparison between participants in the two offices, the average daily workstation electricity consumption was calculated by only considering days when each participant had been present at their respective office and had used their workstation. Whether or not the participant had been at the office was determined by manual examination of each workstation's 6-minute consumption profile for each day. Participant's workstation electricity consumption was normalised by considering the 6-minute profile data obtained through the plug energy monitors. The most frequently recorded power demand over the four weeks was calculated and used as the basis of the normalisation. The 
rationale behind this was that different participant job roles required a different configuration of appliances. For instance, the job roles for certain participants involved building simulation modelling requiring powerful PCs while other participants used laptops. As this study was carried out in a real world environment we were not able to ensure that every participant had the same equipment at their desk. However, as shown in Table 1, the range of equipment did not vary markedly. Differences in available equipment will, of course, add to that individual variability in energy consumption which is not captured by psychological constructs and therefore the percentage of the total variation accounted for by such factors should be considered in this context. Any observation of variation accounted for by psychological factors will be against the background of variation in individual energy use already accounted for by other factors, including variation due to the appliances available.

Table 1: Type and number of small power appliances at workstation in the two buildings.

\begin{tabular}{|l|cc|c|cc|cccc|}
\cline { 2 - 9 } \multicolumn{1}{c|}{} & \multicolumn{2}{c|}{ Screens } & & \multicolumn{2}{c|}{ Desktop } & \multicolumn{3}{c|}{ Desk appliances } \\
\cline { 2 - 10 } \multicolumn{1}{c|}{} & One & Two & Laptop & Small & Large & Fans & Lamps & $\begin{array}{l}\text { Phone } \\
\text { charger }\end{array}$ & $\begin{array}{c}\text { Camera } \\
\text { charger }\end{array}$ \\
\hline Building 1 & 4 & 37 & 33 & 7 & 8 & 5 & 0 & 5 & 2 \\
Building 2 & 7 & 30 & 29 & 8 & 0 & 4 & 1 & 1 & 0 \\
\hline
\end{tabular}

Perhaps because of differences in workstation configuration, electricity consumption also varied greatly between workstations in the two buildings. Building 1 showed average daily workstation consumption of $500 \mathrm{Wh}$ (Figure 3). Building 2 showed average daily workstation consumption $750 \mathrm{Wh}$ (Figure 4). Higher individual consumption over 1,000Wh usually indicates a participant with a large desktop PC used for running modelling software. The BCO (2009) Guide to Specification suggests that a typical workstation load will be around $150 \mathrm{~W}$. This equates to an average daily workstation consumption of 1,350Wh (assuming a standard working day of 9 hours) and is clearly much greater than the average consumption monitored during this study. This lends support to the view that workstation small power loads are being overestimated during the design process (Menezes, 2013). Recently the BCO (2014) have completed a separate workstation monitoring study involving multiple offices in the UK. The results showed a wide range of workstation consumption between $270 \mathrm{Wh}$ to $4,050 \mathrm{Wh}$ (assuming a workstation density of 1 per $10 \mathrm{~m}^{2}$ and a standard working day of 9 hours) but the report emphasises that the majority of occupants had a consumption of less than their previous estimation of $1,350 \mathrm{Wh}$ with the average closer to $900 \mathrm{Wh}$. While this updated figure is still greater than the average consumption in either of the offices monitored during this study it may be that the workstation equipment specified in them is more energy efficient than is typical in the majority of UK offices. 


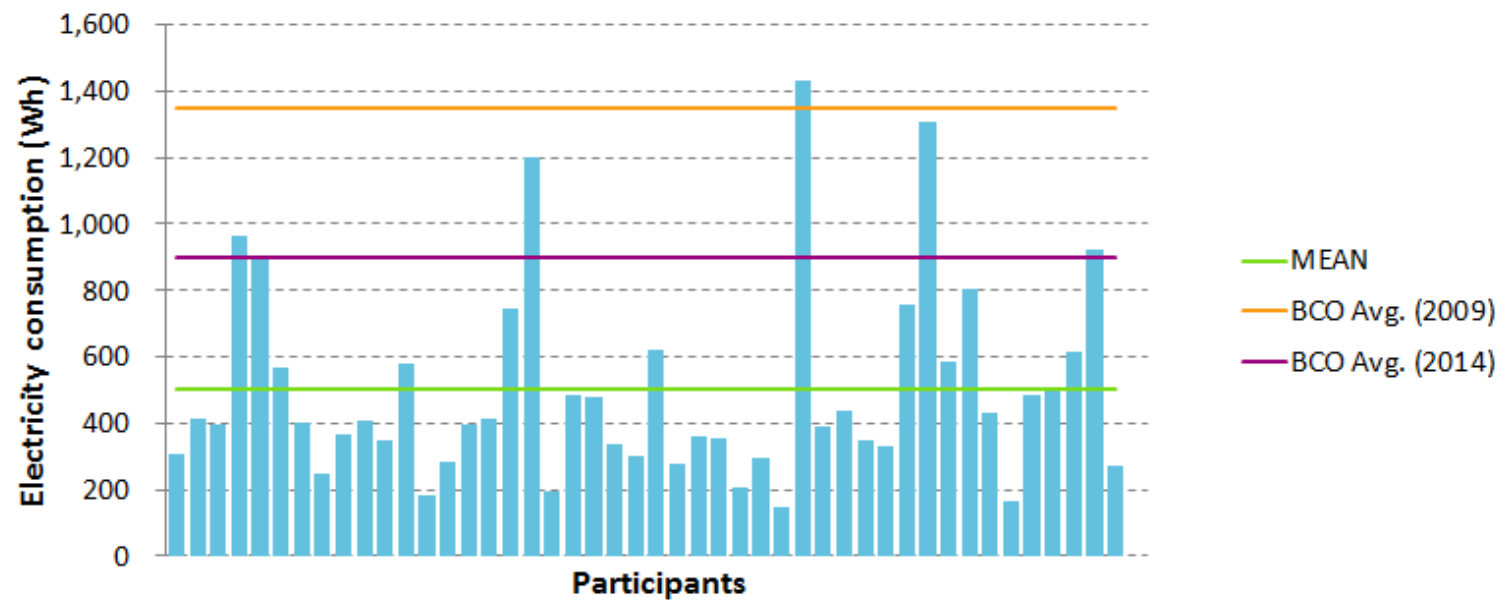

Figure 3: Average daily electricity consumption for each participant at Building 1.

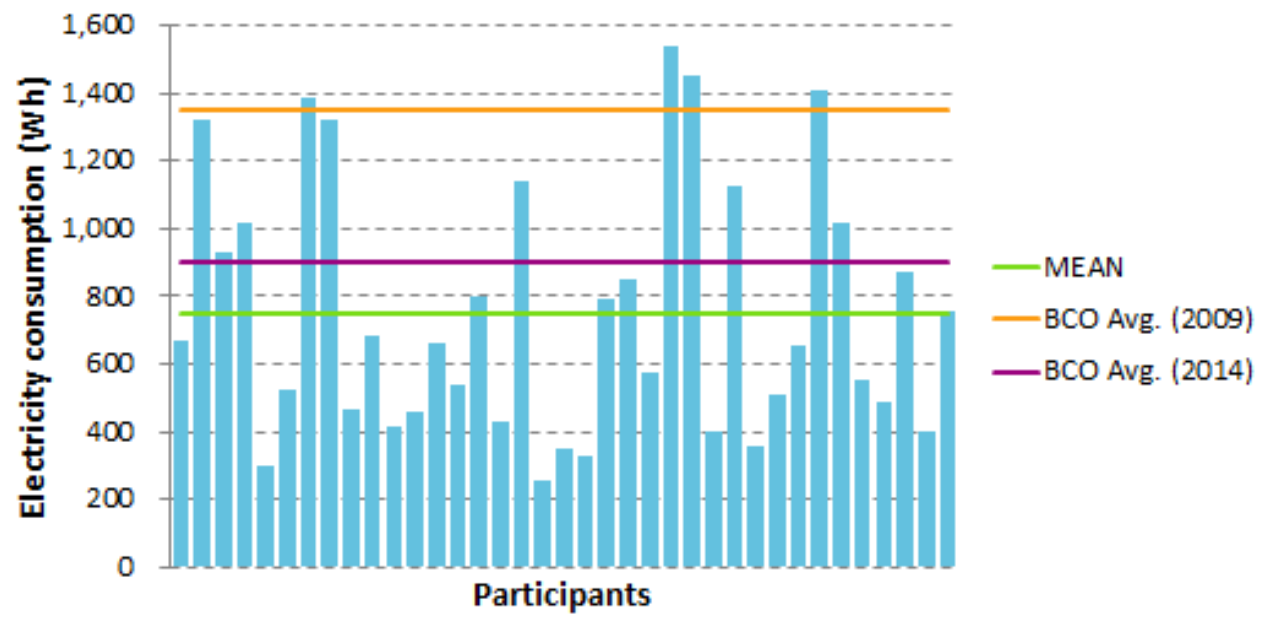

Figure 4: Average daily electricity consumption for each participant at Building 2.

\section{RESULTS}

During analysis attempts were made to identify the workstation consumption overnight (e.g. between 00:00 and 06:00), however, no data were available on when participants might have been at their workstations during this period and ethical approval was not available to obtain such data because of concerns that the information could be used for surveillance and inappropriately used to assess work performance. The consumption for the majority of participants was, however, very low during this period. A multiple linear regression analysis was therefore undertaken to predict the average daily (24-hour) workstation electricity consumption based on the four behavioural constructs for the combined sample for both buildings. The constructs were entered into a stepwise multiple linear regression analysis in the order: behavioural attitude, PBC, subjective norms, and habit. This showed that behavioural attitude alone did not account for a significant proportion of the variation in workstation electricity consumption across the two offices, 
with $\mathrm{R}^{2}=0.002, \mathrm{~F}(1,79)=0.13, p=0.72$. $\mathrm{PBC}$ was then added to the regression model, but this did not significantly add to the predictive value, with $R^{2}$ change $=0.001, F(1,78)=0.119$, $p=0.89$. Next subjective norms was added to the regression model, again this did not significantly increase the predictive value, with $\mathrm{R}^{2}$ change $=0.007, \mathrm{~F}(1,77)=0.57, p=0.85$. When habit was introduced the predictive power of the linear regression model significantly increased and accounted for approximately $11 \%$ of the variation in monthly electricity consumption, with $\mathrm{R}^{2}$ change $=0.11, \mathrm{~F}(1,76)=9.27, p=0.04$.

A linear regression analysis with habit as the only predictor of average daily workstation electricity consumption shows a significant relationship with $\mathrm{R}^{2}=0.11, \mathrm{~F}(1,79)=9.49, p=$ 0.03 . Based on this (and despite the substantial variation in energy use across the buildings), habit alone explains around $11 \%$ of the variation between individuals' workstation electricity consumption across both the buildings. Other, more conscious and deliberate considerations did not, however, account for significant variation in energy use. Figure 5 shows the correlation between the average daily workstation electricity consumption for each participant for both buildings normalised for the installed load against each of the four behavioural constructs.
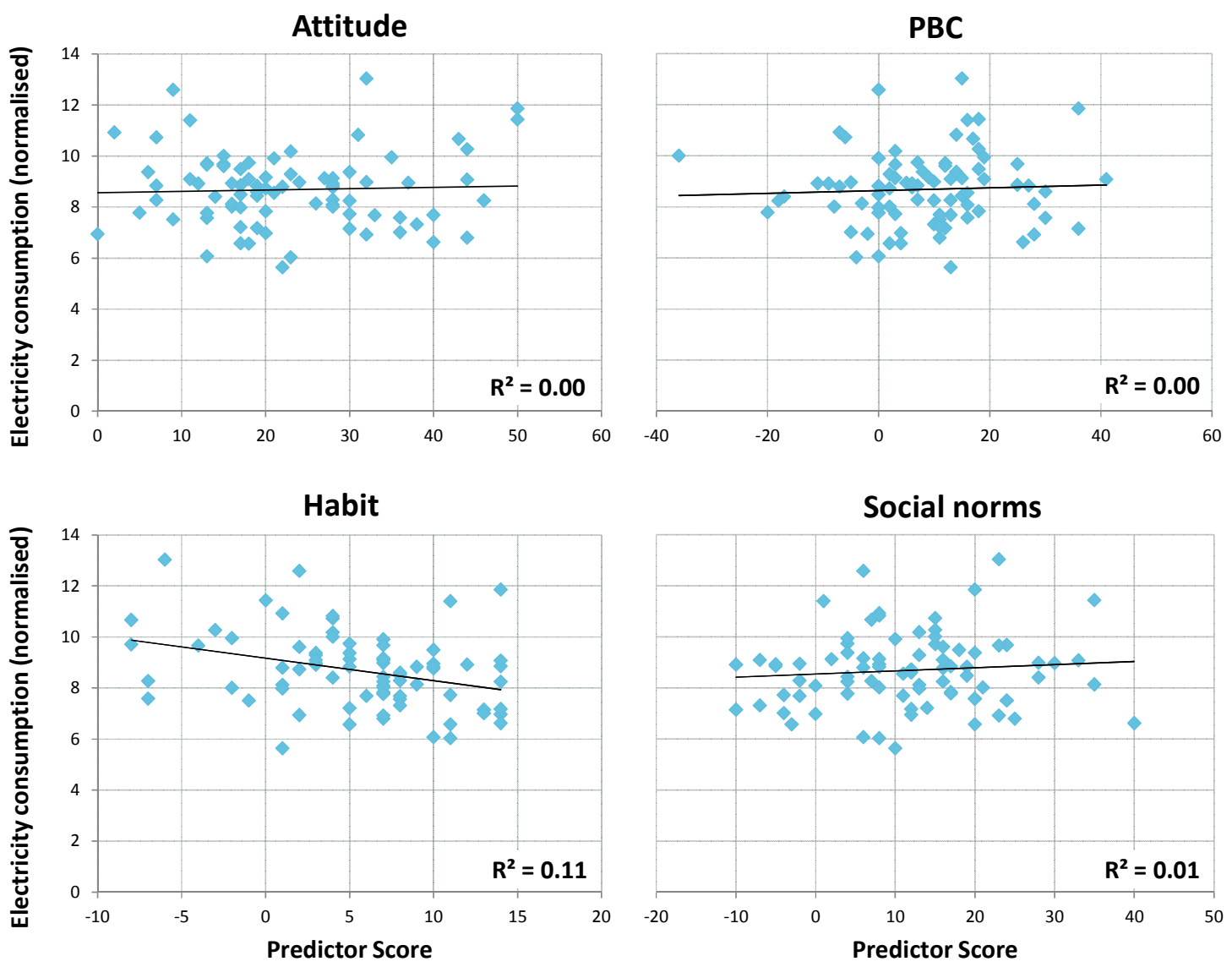
Figure 5: Correlations for each behavioural construct and normalised average daily workstation electricity consumption for both Building 1 and Building 2.

Additionally multiple linear regression analyses for the individual buildings were undertaken. This was to determine whether individual variation in energy consumption within a building might be masked by greater differences in variation between the buildings and, in particular, whether individual differences in psychological constructs might drive individual differences in energy consumption to a greater or lesser degree in each of the buildings. For Building 1 this revealed that behavioural attitude individually did not account for a significant proportion of the variation in workstation electricity consumption, with $\mathrm{R}^{2}=$ $0.02, F(1,42)=0.085, p=0.77$. There was no statistically significant correlation between behavioural attitude scores and average daily workstation consumption. PBC was then added to the regression model, but this did not significantly add to the predictive value, with $\mathrm{R}^{2}$ change $=0.01, \mathrm{~F}(1,41)=0.046, p=0.94$. Next subjective norms was added to the regression model, again this did not significantly increase the predictive value, with $\mathrm{R}^{2}$ change $=0.04, F(1,40)=0.090, p=0.97$. Finally, when habit was introduced the predictive power of the linear regression model increased to account for approximately $19 \%$ of the variation in workstation electricity consumption although this just missed significance, with $\mathrm{R}^{2}$ change $=0.19, \mathrm{~F}(1,39)=9.28, p=0.05$.

Taken individually, none of the predictors showed a significant relationship with average daily workstation electricity consumption, however adding habit as the last element in the stepwise regression resulted in a $p$-value of .05 which is the cut-off point for conventional statistical significance and this value was obtained when any variance shared by habit with constructs entered earlier was already excluded from consideration. Accordingly, a linear regression analysis with habit as the only predictor of average daily workstation electricity consumption was calculated and this showed a significant relationship, with $R^{2}=0.18, F(1$, $42)=9.02, p=0.04$. Based on this, it seems that habit reliably explains around $18 \%$ of the variation between each individual's workstation electricity consumption in Building 1.

In Building 2 the multiple linear regression analysis again showed that behavioural attitude alone did not significantly correlate with workstation electricity consumption, $R^{2}=0.02, F(1$, $35)=0.059, p=0.81$. PBC was then added to the regression model, but again this did not significantly add to the predictive value, $\mathrm{R}^{2}$ change $=0.011, \mathrm{~F}(1,34)=0.218, p=0.81$. Subjective norms was added to the regression model next and again this did not significantly increase the predictive value, $\mathrm{R}^{2}$ change $=0.09, \mathrm{~F}(1,33)=1.26, p=0.31$. However, when lastly habit was added to the linear regression model the predictive power significantly increased to account for approximately $17 \%$ of the variation in workstation electricity consumption, with $\mathrm{R}^{2}$ change $=0.17, \mathrm{~F}(1,32)=2.97, p=0.03$. A linear regression analysis with habit as the only predictor of average daily workstation electricity consumption reveals a significant relationship with $\mathrm{R}^{2}=0.18, \mathrm{~F}(1,35)=7.72, p=0.01$. Based on this, habit 
explains around $18 \%$ of the variation between each individual's workstation electricity consumption in Building 2 as in Building 1.

\section{DISCUSSION}

Results from this study indicate that, of the four assessed behavioural predictors, only habit correlated significantly with average daily workstation consumption. This implies that turning off appliances not in use purely habitually or automatically resulted in reduced electricity consumption relative to those with less established habits. In contrast no relationship was discovered between workstation electricity consumption and the remaining three predictors which form the TPB: behavioural attitudes, subjective norms, and perceived behavioural control. For the combined sample of both offices, habit can explain around $11 \%$ of the observed variation between workstation electricity consumption. This is less than the around $18 \%$ of the variation in workstation electricity observed in each building individually but this reduced figure can easily be explained by the observation that energy use also varied across the buildings, and in a way not accounted for by the habits of the occupants. Given potential differences across the buildings which are to do with the buildings rather than the occupants per se, our results are therefore perfectly understandable and it is reassuring both that the individual estimates for proportion of variation in energy use explained by habit alone were consistent in each of the buildings individually, and that the combined sample from both buildings still showed substantial effects of habit even after such building-specific influences had been included.

In contrast, none of the TPB constructs show a significant correlation with electricity consumption, this is contrary to the results of the previous study (Menezes et al., 2012b) where perceived behavioural control show a significant relationship to energy use. However, the previous study was carried out in a multi-tenanted office building where the occupants in different metered zones had varying levels of control over lighting and small power appliances. It is plausible that percieved behavioural control is an important factor when considering group interactions with building service systems in general, but not as important when considering small power consumption in an office where everyone effectively has (or perceives themselves to have) the same level of control over small power appliances. The results of the Menenzes et al. (2012b) study need to be interpreted cautiously in any case however, because of the relatively small sample size $(\mathrm{N}=27)$ which is low for an analysis of this type and may not be sufficiently representative of the general population. This is not a problem for the current study as the overall sample size across the two buildings is nearly three times the size of the Menezes et al. sample and, additionally, the same general patterns are observed in both buildings when examined independently.

The results of the study presented here could prove extremely useful for employee engagement campaigns. The building occupants may often be well-disposed towards energy 
conservation but are prone to inadvertent energy use from actions made in error, such as forgetting to switch off their computer at the end of the day. The standard method of conducting information intensive campaigns to encourage occupants to switch off appliances when not required may have little impact on actual behaviour, because they focus disproportionately on attitudes. We do not claim that there is no connection between attitudes and energy-use. As noted elsewhere, in our study, many factors may have militated against finding such a connection. However, these same factors (e.g., the homogeneity of the work-environment and tasks for most office workers and the subsequent impact upon workstation plug loads) should also have acted to reduce the correlation between habit and energy use which, nonetheless, remained significant.

Attempts to promote energy conservation amongst occupants may therefore yield more effective results when focussed also on automatic habitual behaviour. Thorough longitudinal empirical research in this field is rare - partly as a result of the difficulty in empirically measuring habits. However, in one example, Lally et al. (2010) measured habit strength of groups using the SRHI. Their results suggested that the average time for a habit to "strongly" form is 69 days when the action is repeated once per day in a stable context. With regards to small power consumption in buildings, the most obvious first steps in encouraging behaviour to become automatic and habitual are to simplify the actions required, and to ensure that highly salient cues to action are present in the environment at the point at which the action is required (Norman, 2013; Tetlow et al., 2014). For example, in terms of small power consumption, a single unambiguous on/off switch located so that it is visible and easily reached at the point at which the device is no longer required is obviously more conducive to habitually conserving energy than one that is a less obvious, or less easily operated, at the time at which an occupant might wish to turn power off. The time and effort needed to restart the device must also be considered - any powered device which is easily turned off will not be turned off habitually if it cannot also be turned back on again when needed with a minumum of inconvenience. These principles are welldocumented in the study of decision-making (Payne et al., 1993) and human-computer interaction (Payne et al., 2001) and can be applied to minimise excess energy use within the built environment also.

In summary, while built environment models now acknowledge the influence of occupant psychology, they remain simplistic in their conception of the drivers of occupant behaviour and are not routinely used to influence the design of buildings. They tend to describe the building occupants as rational, independent individuals who formulate intention based on their response to external environmental variables and their internal attitudes, both of which may be too broadly construed with too much emphasis placed upon attitude and conscious intention. The findings presented here indicate that this interpretation of behaviour is likely to be insufficient. In this study as well as previous work (Menezes et al., 2012b), the attitudes of office occupants displayed no clear relationship with energy consumption for small power use or lighting. Although the study reported here only 
examined small power consumption in offices it is likely that occupants interact with other building systems (such as lighting and windows) in a similar manner. It is reasonable to suppose that such behaviours as window opening/ closing could be characterized by some general rule or mode of operation (e.g., indoor thermal comfort) that does not apply to the plug-load equipment studied here. However, the suggestion that habit may play a part in such behaviours is not necessarily inconsistent with such a rule-based approach. Rather, the regression model simply aims to estimate the individual variation (perhaps in stochastically applying such a rule) that could be assigned to habitual or automatic behaviours. If, as seems likely, opening a window at the start of the day (and, crucially, remembering to close it at the end of the day) is moderated by habitual modes of action (e.g., "I always open the window first thing" or "I always forget to close the window when leaving the office") then the extent to which this affects energy consumption is a matter for further empirical enquiry. Fabi et al. (2012) point out that such "psychological" aspects of occupant behaviour in these circumstances have not been investigated to the same degree as environmental variables such that current models do not consider that wondow operation could be a joint function of habit/ routine and response to environmental conditions. To improve built environment models of behaviour a more sophisticated representation of the occupant's internal drivers could be extremely beneficial and this may be obtained by methods similar to those outlined here.

To our knowledge, although the $\mathrm{SRHI}$ is recommended as a useful tool for measuring habitual pro-environmental behaviour (Darnton et al., 2011), this is the first time it has been applied to occupant related energy consumption in office buildings. As such these results require verification across a range of offices and building specifications. It would also be of interest to apply this method to other specific occupant behaviours within the built environment such as window opening.

\section{CONCLUSIONS}

Current consideration of the psychology of building occupants in both behavioural models and occupant engagement campaigns to motivate energy conservation are predicated on the assumption of a direct link between pro-environmental attitudes and pro-environmental behaviour. Evidence suggests that this conception is overly simplistic as it does not account for other influential factors, particularly habitual behaviour. This study investigates these other influential factors by correlating behavioural construct scores with direct measurements of electricity consumption at occupant workstations. Measurements and surveys were carried out for 81 occupants in two open plan office buildings. The findings from this study showed that habit explains around $11 \%$ of the variation in individual's workstation electricity consumption across the two office buildings. Automaticity of the action was identified as a significant influence on whether occupants turned off appliances when not in use. No correlation was found with their environmental attitudes, the influence of the actions of those around them, or whether they perceived it to be under their control. 
This finding has clear implications for behavioural models for the design of new buildings if such models aspire to identify the individual causes of energy use and, more particularly, for employee engagement campaigns for existing buildings. A shift of focus is indicated away from assumptions of a direct link between environmental attitudes and behaviour towards the occupant's automatic and habitual behaviour.

\section{ACKNOWLEDGEMENTS}

The corresponding author would like to thank the EPSRC and AECOM for funding this research.

\section{REFERENCES}

Ajzen, I., 1991. The Theory of Planned Behaviour. Organizational Behaviour and Human Decision Processes, 50(2), 179-211.

Ariely, D. 2009. Predictably Irrational: The Hidden Forces that Shape Our Decisions. London: HarperCollins.

Armitage, C. \& Conner, M. 2001. Efficacy of the theory of planned behaviour: a metaanalytic review. British Journal of Social Psychology, 40, 471-499.

Azar, E. \& Menassa, C.C. 2012. A comprehensive analysis of the impact of occupancy parameters in energy simulation of office buildings. Energy \& Buildings, 55, 841-853.

Bamberg, S. \& Schmidt, P. 2003. Incentives, Morality, or Habit? Predicting Students' Car Use for University Routes With the Models of Ajzen, Schwartz, and Triandis. Environment and Behaviour, 35(2), 264-285.

BCO. 2009. Guide to Specification. London: British Council of Offices.

BCO. 2014. Desk Power Load Monitoring. London: British Council of Offices.

Bourgeois, D. 2005. Detailed occupancy prediction, occupancy-sensing control and advanced behavioral modeling within whole-building energy simulation. Thesis (Ph.D), I'Universite Laval, Quebec, Canada.

BRECSU. 2000. Energy Consumption Guide 19: Energy use in offices. Watford: Building Research Energy Conservation Support Unit.

Carbon Trust. 2013. Creating an awareness campaign. CTG056. London: Carbon Trust. 
Chatterton, T. 2011. An Introduction to Thinking About 'Energy Behaviour': a multi-model approach. Department of Energy and Climate Change (DECC) report, December 2011.

CIBSE. 2009. CIBSE Guide H: Building Control Systems. $2^{\text {nd }}$ Edition. London: Chartered Institution of Building Service Engineers.

Darnton, A., Verplanken, B., White, P. \& Whitmarsh, L. 2011. Habits, Routines and Sustainable Lifestyles: A summary report to the Department for Environment, Food and Rural Affairs. AD Research \& Analysis for Defra, London.

DECC. 2014. Energy Consumption in the UK (2014). Data from ECUK Table 5.14. [Online]. Available at: https://www.gov.uk/government/statistics/energy-consumption-in-theuk Accessed: 28th September 2014.

DCLG. 2013. Approved Document L2A: Conservation of fuel and power in new buildings other than dwellings. The Building Regulations 2000. London: Department for Communities and Local Government.

Evans, J. 2008. Dual-Processing Accounts of Reasoning, Judgment, and Social Cognition. Annual Review of Psychology, 59, 255-278.

Fabi, V., Andersen, R.V., Corgnati, S. \& Olesen, B.W. 2012. Occupants' window opening behaviour: A literature review of factors influencing occupant behaviour and models. Building \& Environment, 58, 188-198.

Fabi, V., Camisassi, V., Causone, F., Corgnati, S.P. \& Anderson, R. 2014. Light switch behaviour: occupant behaviour stochastic models in office buildings. Proceedings of $8^{\text {th }}$ Windsor Conference 2014, London: Network for Comfort and Energy Use in Buildings.

Francis, J., Eccles, M., Johnston, M., Walker, A., Grimshaw, Foy, R., Kaner, E., Smith, L. \& Bonetti, D. 2004. Constructing Questionnaires Based on The Theory of Planned Behaviour - A Manual for Health Services Researchers. Newcastle upon Tyne: Centre for Health Services Research, University of Newcastle.

Gardner, B., Abraham, C., Lally, P. \& de Bruijn, G-J. 2012. Towards parsimony in habit measurement: Testing the convergent and predictive validity of an automaticity subscale of the Self-Report Habit Index. Journal of Behavioural Nutrition and Physical Activity, 10:102. 
Gill, Z., Tierney, M., Pegg, I. \& Allan, N. 2010. Low-energy dwellings: the contribution of behaviours to actual performance. Building Research \& Information, 38(5), 491-508.

Haldi F. \& Robinson, D. 2009. Interactions with window openings by office occupants. Building \& Environment, 44, 2378-2395.

Herkel, S., Knapp, U. \& Pfafferott, J. 2008. Towards a model of user behaviour regarding the manual control of windows in office buildings. Building \& Environment, 43(4), 588600.

Hoes, P., Hensen, J. L. M., Loomans, M. G. L. C., de Vries, B. \& Bourgeois, D. 2009. User behavior in whole building simulation. Energy \& Buildings, 41(3), 295-302.

Hong, T., \& Lin H.-W. 2012. Occupant Behavior: Impact on Energy Use of Private Offices. Proceedings of Asim IBSPA Asia Conference, 2012.

Hong, T., D’Oca, S., Turner, W.J.N., \& Taylor-Lange, S.C. 2015. An ontology to represent energy-related occupant behavior in buildings. Part I: Introduction to the DNAs framework, Building and Environment, in press. http://dx.doi.org/10.1016/j.buildenv.2015.02.019

Huebner, G.M., Cooper, J. \& Jones, K. 2013. Domestic energy consumption - What role do comfort, habit, and knowledge about the heating system play? Energy \& Buildings, $66,626-636$.

Kahneman, D. 2011. Thinking, fast and slow. London: Penguin.

Kempton, K. \& Lutzenhiser, L. 1992. Introduction to special issue on air-conditioning: The Interplay of Technology, Culture and Comfort. Energy \& Buildings, 18(3-4), 171-176.

Kollmuss, A. \& Agyeman, J. 2002. Mind the Gap: Why do people act environmentally and what are the barriers to pro-environmental behaviour? Environmental Education Research, 8(3), 239-260.

Lally, P., Cornelia, H.M., van Jaarsveld, H., Henry, W., Potts, W. \& Wardle, J. 2010. How are habits formed: Modelling habit formation in the real world. European Journal of Social Psychology, 40, 998-1009.

Lo, S.H., Peters, G.-J.Y. \& Kok, G. 2012. Energy-Related Behaviors in Office Buildings: A Qualitative Study on Individual and Organisational Determinants. Applied Psychology, 61(2), 227-249. 
Love, J.A. 1998. Manual switching patterns observed in private offices. Lighting Research \& Technology, 30(1), 45-50.

Masoso, O.T. \& Grobler, L.J. 2010. The dark side of occupants' behaviour on building energy use. Energy \& Buildings, 42, 173-177.

McCrae, R.R. \& John, O.P. 1992. An introduction to the Five-Factor model and its applications. Journal of Personality, 60(2), 175-215.

Menezes, A., Cripps, A., Bouchlaghem, D. \& Buswell, R. A., 2012a. Predicted vs. actual energy performance of non-domestic buildings: Using post-occupancy evaluation data to reduce the performance gap. Applied Energy, 97, 355-364.

Menezes, A.C., Tetlow, R., Beaman, C.P., Cripps, A., Bouchlaghem, D, \& Buswell, R. 2012b. Assessing the Impact of Occupant Behaviour on Electricity Consumption for Lighting and Small Power in Office Buildings. In: Proceedings on the International Conference of Architecture Engineering and Construction (AEC2012), Sao Paulo, Brazil. $15^{\text {th }}-17^{\text {th }}$ August 2012.

Menezes, A.C. 2013. Improving predictions of operational energy performance through better estimates of small power consumption. Thesis (EngD), Centre for Innovative and Collaborative Construction Loughborough University, Loughborough, UK.

Mulville, M., Jones, K., \& Huebner, G. 2014. The potential for energy reduction in UK commercial offices through effective management and behaviour change. Architectural Engineering and Design Management, 10, 79-90.

Newsham, G. R. 1994. Manual Control of Window Blinds and Electric Lighting: Implications for Comfort and Energy Consumption. Indoor and Built Environment, 3(3), 135-144.

Nicol, J.F. 2001. Characterising occupant behaviour in buildings: towards a stochastic model of occupant use of windows, lights, blinds, heaters and fans. In: Proceedings of the seventh international IBPSA conference, Rio, Brazil, 2001.

Norman, D. A. 2013. The design of everyday things. $2^{\text {nd }}$ edition. New York: Basic books.

Norman, D. A., \& Shallice, T. (1986). Attention to action: Willed and automatic control of behaviour. In: R. J. Davidson, G. E. Schwartz \& D. Shapiro (Ed.s). Consciousness and self-regulation. New York: Plenum Press. 
Owens, S. \& Driffill, L. 2008. How to change attitudes and behaviours in the context of energy. Energy Policy, 36(12), 4412-4418.

Page, J., Robinson, D., Morel, N. \& Scartezzini, J.L. 2008. A generalised stochastic model for the simulation of occupant presence. Energy \& Buildings, 40, 83-98.

Paunonen, S.V. \& Ashton, M.C. 2001. Big Five Factors and Facets and the Prediction of Behaviour. Journal of Personality and Social Psychology, 81(3), 524-539.

Payne, J. W., Bettman, J. R., \& Johnson, E. J. 1993. The adaptive decision maker. Cambridge: Cambridge University Press.

Payne, S. J., Howes, A., \& Reader, W. R. 2001. Adaptively distributing cognition: A decision making perspective on human-computer interaction. Behaviour \& Information Technology, 20, 339-346.

Pigg, S., Eilers, M. \& Reed, J. 1996. Behavioural aspects of lighting and occupancy sensors in private offices: A case study of a university office building. In: Proceedings of the 1996 ACEEE summer study on energy efficiency in buildings, 161-168.

Reinhardt, C.F. 2004. Lightswitch 2002: A Model for Manual Control of Electric Lighting and Blinds. Solar Energy, 77, 15-28.

Ross, L. 1977. The Intuitive Psychologists and His Shortcomings: Distortion in the Attribution Process. in ed. Advances in Experimental Social Psychology, 10, New York: Academic Press.

Ruyssevelt, P. \& Robertson, C. 2013. CarbonBuzz Data Audit III - v 2.1. London: UCL Energy Institute.

Sheeran, P. 2002. Intention-behaviour relations: A conceptual and empirical review. European Review of Social Psychology, 12(1), 1-36.

Storms, M. 1973. Videotape and the attribution process: Reversing actors' and observers' points of view. Journal of Personality and Social Psychology, 27, 165-175.

Tetlow, R. M., Beaman, C. P., Elmualim, A. A. \& Couling, K. 2014. Simple prompts reduce inadvertent energy consumption from lighting in office buildings. Building \& Environment, 81, 234-242.

Triandis, H. C. 1977. Interpersonal behavior. Monterey, CA: Brooks/Cole. 
Turner, W. \& Hong, T. 2013. A technical framework to describe occupant behavior for building energy simulations. In: conference proceedings BECC 2013, Sacramento, US.

Ucci, M., Domenech, T., Ball, A., Whitley, T., Wright, C., Mason, D., Corrin, K., Milligan, A., Rogers, A., Fitzsimons, D., Gaggero, C. \& Westaway, A. 2012. Behaviour change potential for energy saving in non-domestic buildings: Development and pilot-testing of a benchmarking tool. Building Services Engineering Research and Technology, 35(1), 36-52.

UKGBC (UK Green Building Council). 2014b. Building Zero Carbon - The case for action: Examining the case for action on Zero Carbon 2019 non-domestic buildings. UKGBC, February 2014.

Verplanken, B. \& Orbell, S., 2003. Reflections on past behavior: A self-report index of habit strength. Journal of Applied Social Psychology, 33(6), 1313-1330.

Yu, Z., Fung, B. C. M., Haghighat, F., Yoshino, H., \& Morofsky, E. 2011. A systematic procedure to study the influence of occupant behavior on building energy consumption. Energy \& Buildings, 43(6), 1409-1417.

Yun, G. Y. \& Steemers, K. 2008. Time-dependent occupant behaviour models of window control in summer. Building \& Environment, 43(9), 1471-1482. 